2020-12-21

\title{
Spectral Absorption Coefficient of Additive Manufacturing Materials
}

Nicholas J. Wallace

Brigham Young University - Provo

Matthew R. Jones

Brigham Young University - Provo

Nathan B. Crane

Brigham Young University - Provo, nbcrane@byu.edu

Follow this and additional works at: https://scholarsarchive.byu.edu/facpub

Part of the Manufacturing Commons, and the Other Mechanical Engineering Commons

\section{Original Publication Citation}

Nicholas J. Wallace, Matthew R. Jones, Nathan B. Crane, "Spectral Absorption Coefficient of Additive Manufacturing Materials," ASME Journal of Thermal Sciences and Engineering Application, TSEA-20-1502S, Published online 10/21/2020, https://doi.org/10.1115/1.4048836.

\section{BYU ScholarsArchive Citation}

Wallace, Nicholas J.; Jones, Matthew R.; and Crane, Nathan B., "Spectral Absorption Coefficient of Additive Manufacturing Materials" (2020). Faculty Publications. 5339.

https://scholarsarchive.byu.edu/facpub/5339

This Peer-Reviewed Article is brought to you for free and open access by BYU ScholarsArchive. It has been accepted for inclusion in Faculty Publications by an authorized administrator of BYU ScholarsArchive. For more information, please contact ellen_amatangelo@byu.edu. 


\title{
Spectral Absorption Coefficient of Additive Manufacturing Materials
}

\author{
Nicholas J. Wallace, Matthew R. Jones, Nathan B. Crane \\ Department of Mechanical Engineering \\ Brigham Young University \\ Engineering Building, Campus Dr, Provo, UT 84602
}

\begin{abstract}
Active thermography techniques are of interest for quality assurance of additive manufacturing processes. However, accurate measurements of thermophysical properties of materials are required to successfully implement active thermography. In particular, the spectral absorption coefficient of materials commonly used in additive manufacturing must be known to accurately predict the spatial distribution of thermal energy generated from absorption of power emitted by a laser or pulsed flash lamp. Accurate measurements of these optical properties are also needed to develop greater understanding of additive manufacturing processes that rely on radiative heat transfer to fuse powders. This paper presents spectral absorption coefficient measurements and uncertainty estimates of fully and partially dense ABS, PLA, and Polyamide 12 samples.
\end{abstract}

\section{INTRODUCTION}

Additive Manufacturing (AM) has potential benefits in geometric freedom and reduced lead times but is subject to various sources of defects [1]. Techniques are needed to detect these defects during production. Currently, researchers seek to use active thermography to detect defects during AM processes [2-4].

Existing thermography models use transient surface temperature measurements to predict the existence and location of defects [5-8]. The optical and thermophysical properties of the material are assumed to be known in these models, so accurate values are required to successfully determine whether defects exist and to estimate their location. These models also 
depend on approximations regarding the depth of the region in which the incident radiative pulse is converted to thermal energy within the sample. The materials analyzed with these models are often approximated as highly absorbing $\left(\kappa_{\lambda} \rightarrow \infty\right)$, so the incident pulse is assumed to be completely absorbed within an infinitesimal layer at the surface [5-8].

Transient surface temperature measurements used in thermography models depend significantly on the depth at which radiation is absorbed. Thus, thermography models which approximate radiation being absorbed entirely at the surface are not suitable for analysis of materials that have large absorption depths. However, thermography models which account for in-depth absorption can be used to predict the transient temperature of highly absorptive, even semitransparent material [9].

The relationship between in-depth absorption and transient surface temperature is illustrated in Figure 1 by comparing data retrieved from a numerical simulation. This simulation models the response of an ABS sample irradiated with a short pulse when the spectral absorption coefficient, $\mathrm{k}_{\lambda}$, was set to $0.025 \mu \mathrm{m}^{-1}$ and when it approached infinity. The spectral absorption coefficient determines the exponential rate at which spectral intensity decreases as it propagates into a material. Thus, it is used to determine the depth of the region in which radiative heating occurs. The simulation results demonstrate that surface temperature profiles depend significantly on whether in-depth absorption is included in a thermography model or not.

Thermography models typically neglect in-depth absorption effects and assume that radiation is absorbed entirely at the surface $\left(\kappa_{\lambda} \rightarrow \infty\right)$ [5-8]. Since the absorption coefficients of metals are large, surface absorption may be a reasonable assumption for metal AM processes. 
However, the absorption coefficients of polymers commonly used in AM processes are relatively low [10-11]. This increased absorption depth affects the surface temperature profiles used in typical thermography models and can result in inaccurate predictions regarding the existence and location of defects. Therefore, in-depth absorption effects should be included when active thermography is applied to polymer AM processes.

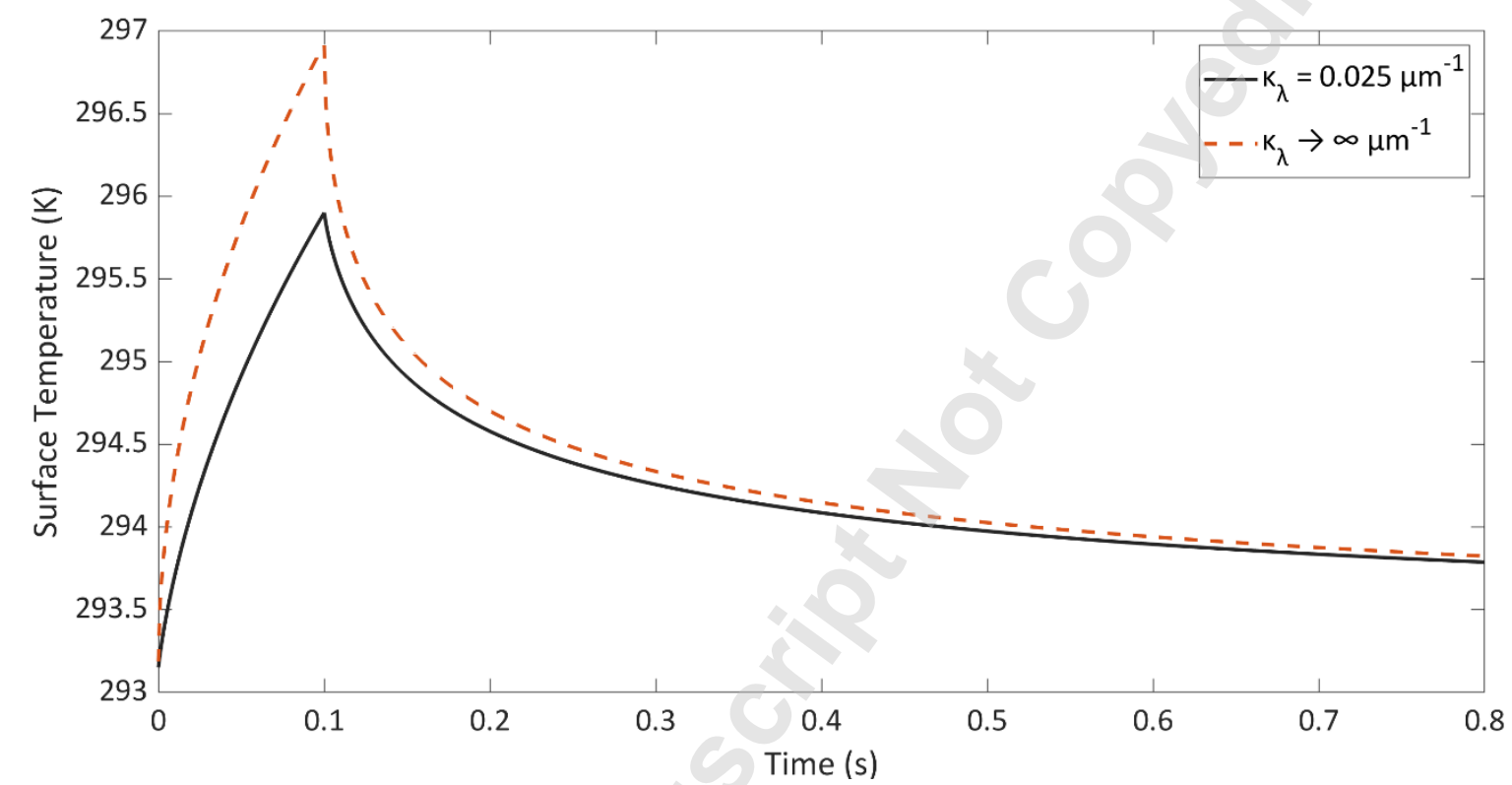

Figure 1: Surface temperature response of an ABS sample irradiated at $660 \mathrm{~nm}$ with $6000 \mathrm{~W} / \mathrm{m}^{2}$ for $0.1 \mathrm{~s}$. The data was retrieved from a 1D COMSOL simulation modeled with the properties of $\operatorname{ABS}\left(\rho=1020 \mathrm{~kg} / \mathrm{m}^{3}, \mathrm{cp}=1386 \mathrm{~J} /(\mathrm{kg} \mathrm{K})\right.$, and $\left.\mathrm{k}=0.2256 \mathrm{~W} /(\mathrm{m} \mathrm{K})\right)$. The 791,000 element, $8 \mathrm{~mm}$ thick model was thermally insulated on all sides except for the top, which was irradiated and convectively cooled $\left(\mathrm{h}=10 \mathrm{~W} /\left(\mathrm{K} \mathrm{m}^{2}\right)\right)$. Transient surface temperatures are presented when $\mathrm{K}_{\lambda}=$ $0.025 \mu \mathrm{m}^{-1}$ and when $\mathrm{K}_{\lambda} \rightarrow \infty$.

The objective of this paper is to present spectral absorption coefficients for some common AM polymers at wavelengths that are used in additive manufacturing for sintering material and performing quality control with active thermography. Traditionally, $\mathrm{CO}_{2}$ lasers have been used in AM to sinter material by emitting infrared radiation for short times ( $1 \mathrm{~ms})$. However, researchers have recently demonstrated that sintering material with radiation in the visible spectrum over longer times ( $\sim \mathrm{s})$ can improve the mechanical properties of the final 
part $[12,13]$. The metal halide bulb used to sinter polymer in these studies has also been used to perform active thermography [2-3]. Because of this, absorption coefficients will be presented over the spectrum of a metal halide bulb as well as two specific wavelengths within the visible spectrum. Spectral absorption coefficient measurements for AM polymers have already been measured in the terahertz or UV regime [10-11,14], but the measurements presented in this paper are unique because they primarily lie in the visible spectrum. It is anticipated that these measurements will also increase understanding of the differences between laser sintering, multi-jet fusion, and projection-sintering AM processes.

\section{METHODS}

A mathematical expression for the spectral absorption coefficient of an AM polymer is obtained by analyzing the scenario illustrated in Figure 2.

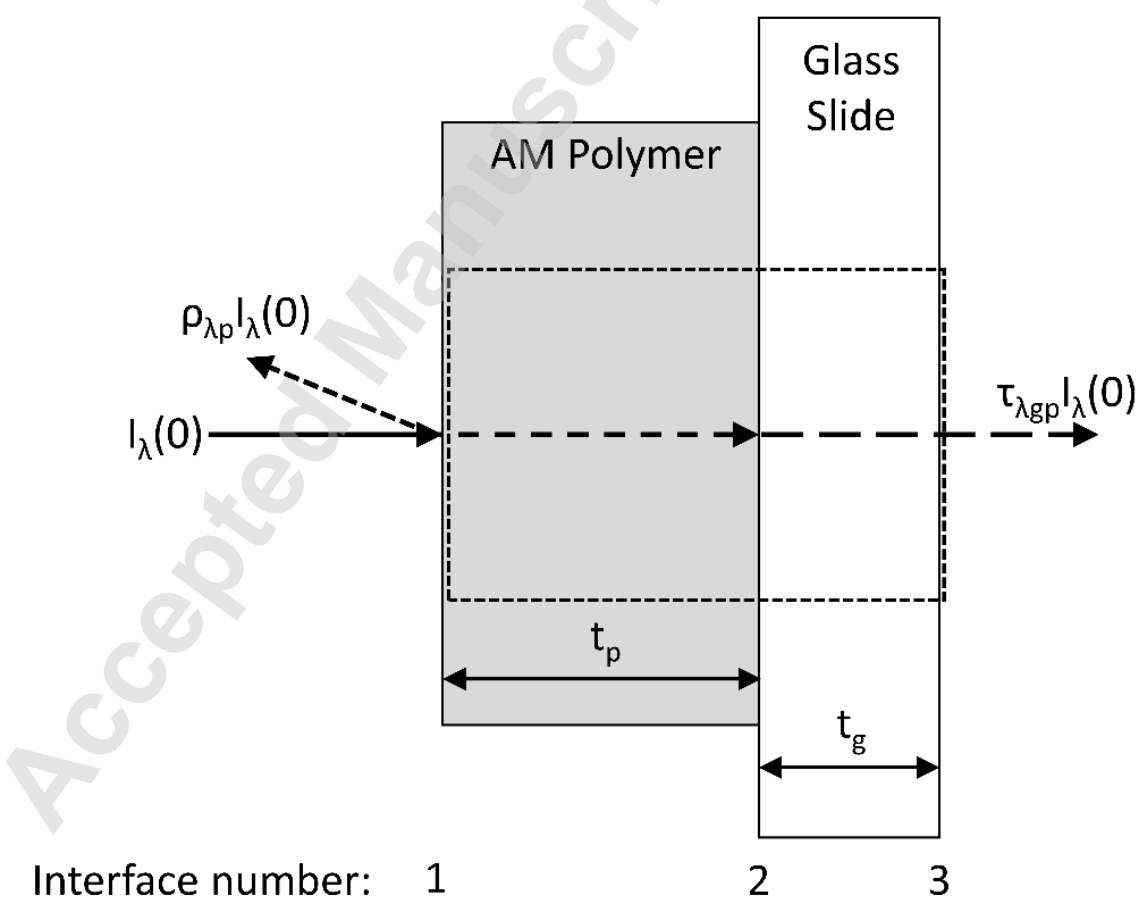

Figure 2: Illustration of the spectral intensity irradiating a black AM polymer fused to a glass slide. The indicated system (dotted rectangle) excludes intensity reflected off interface 1 , and includes intensity reflected off interface 3.

TSEA-20-1503 Wallace et al. 4 
In this specific scenario, a black AM polymer (ABS, PLA, or Polyamide 12) was fused to a glass slide. It was assumed that this system was non-scattering and non-emitting, and that multiple internal reflections were negligible. Justification for the assumptions and simplifications used in the model will be discussed in the methods section under the subheading: "Justification of Assumptions and Simplifications". The spectral absorption coefficient of the AM polymer shown in Figure 2 was defined by Eq. (1) [15]. A complete derivation of this expression is provided in the supplemental information.

$$
\kappa_{\lambda p}=\frac{\ln \left(\frac{\left(1-\rho_{\lambda p}^{\perp \perp}\right) \tau_{\lambda \mathrm{g}}^{\perp \perp}}{\tau_{\lambda \mathrm{gp}}^{\perp \perp}}\right)}{t_{p}}
$$

Therefore, spectral absorption coefficients of AM polymers fused to glass slides may be calculated using measurements of the spectral, normal-normal transmissivity of the polymerglass sample $\left(\tau_{\lambda \mathrm{gp}}^{\perp \perp}\right)$, the spectral, normal-normal transmissivity of the glass slide $\left(\tau_{\lambda \mathrm{g}}^{\perp \perp}\right)$, the spectral, normal-normal reflectivity of the polymer $\left(\rho_{\lambda p}^{\perp \perp}\right)$, and the thickness of the polymer $\left(t_{p}\right)$. A Labsphere RT-060 integrating sphere and a micrometer were used to perform these measurements as described below.

\section{Transmissivity Measurements}

The integrating sphere can be used to measure the spectral, normal-hemispherical transmissivity without any modifications. However, because the material was assumed to be non-scattering, the spectral, normal-hemispherical transmissivity measured with the integrating sphere and the spectral, normal-normal transmissivity used in the absorption coefficient 
calculations are equivalent. The process for measuring the spectral, normal-hemispherical transmissivity was as follows.

Radiation from a laser or a projector ( $\sim 9 \mathrm{~mm}$ diameter beam) was directed through the aperture of the integrating sphere. This light was reflected off the inner surface of the sphere multiple times until absorbed by a silicon photodiode. The current generated by the photodiode was then measured using a multimeter with a $0.1 \mathrm{nA}$ resolution. These current readings are proportional to the power incident on the detector.

Samples of various compositions and thicknesses were then placed in front of the aperture. The ratio between the photodiode current when the radiation was obstructed by a sample and the photodiode current when the radiation entered the sphere freely gives the normal-hemispherical transmissivity of the sample [16]. This process is illustrated in Figure 3.

Dark current effects were subtracted from the measurements as shown in Eq. (2). Subscripts " $m$ " and " $d$ " indicate whether the light source was on or off while the photodiode current was measured. The numerator of this equation represents the difference between the currents measured from the photodiode when the light source was on and off, while a sample was mounted in front of the aperture as shown in Figure 3B. The denominator contains photodiode current measurements when the aperture was left uncovered as shown in Figure 3A. As previously stated, the material was assumed to be non-scattering, thus, the spectral, normal-hemispherical transmissivity and the spectral, normal-normal transmissivity are both described by Eq. (2).

$$
\tau_{\lambda}^{\perp \perp}=\tau_{\lambda}^{\perp \rho}=\frac{\left(I_{m}-I_{d}\right)_{s}}{\left(I_{m}-I_{d}\right)_{e}}
$$



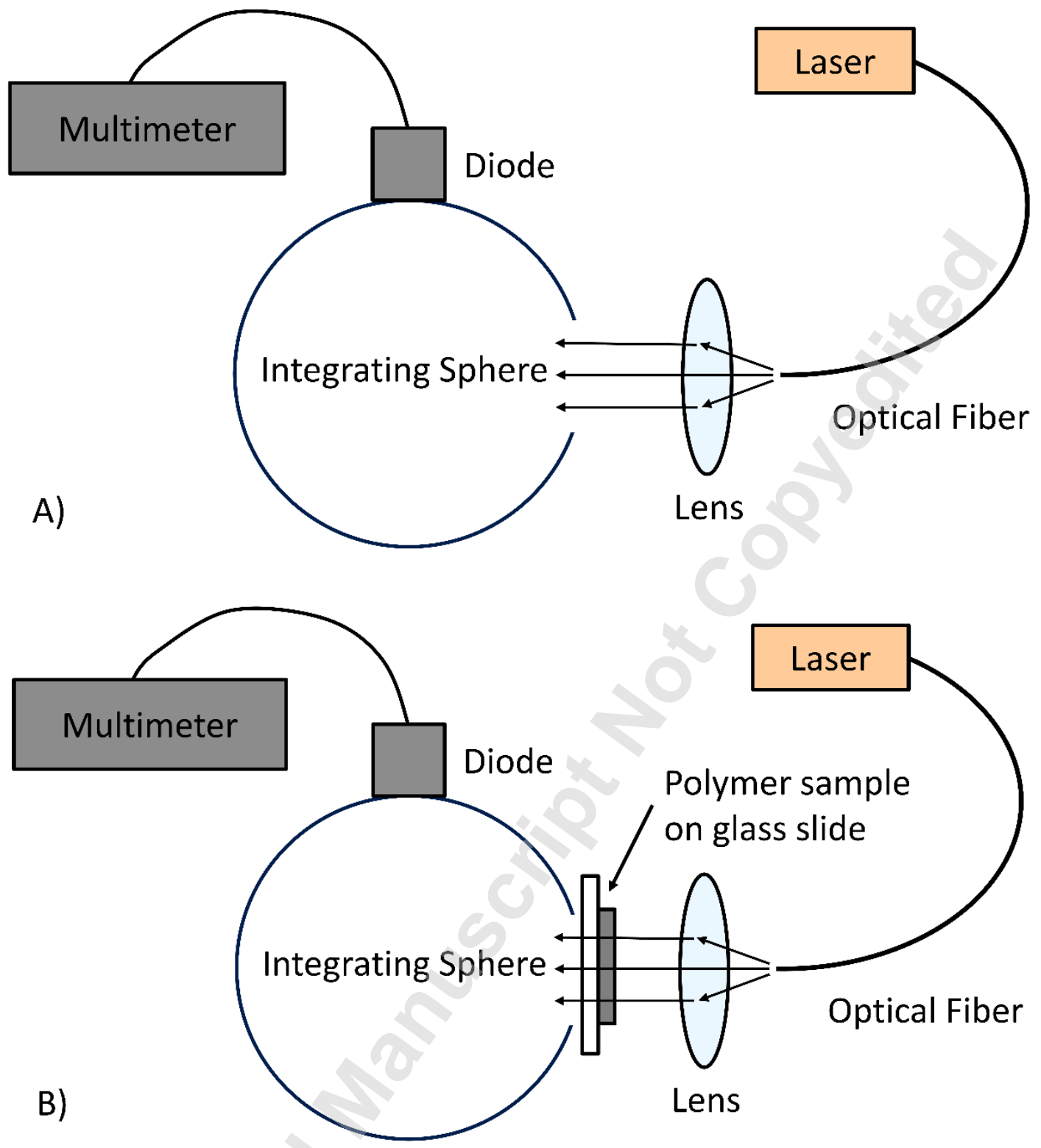

Figure 3: Process for spectral, normal-hemispherical transmissivity measurements using an integrating sphere. A) Radiation enters the sphere unobstructed and current is measured from a photodiode. B) Radiation is obstructed by a sample and current is measured from a photodiode.

\section{Reflectivity Measurements}

The integrating sphere can be used to measure the spectral, directional-hemispherical reflectivity as illustrated in Figure 4 [16]. The spectral, normal-normal reflectivity used to 
calculate the spectral absorption coefficient was approximated by using these spectral, directional-hemispherical reflectivity measurements. The validity of this approximation is discussed in the methods section under the subheading "Justification of Assumptions and Simplifications".

The process for measuring the spectral, directional-hemispherical reflectivity was similar to that of the spectral, normal-hemispherical transmissivity with two differences. First, the sample shown in Figure 3B was moved to the opposite side of the sphere, so the collimated beam ( $\sim 9 \mathrm{~mm}$ diameter) entered the sphere unattenuated. Second, a reflectance calibration standard $\left(\rho_{\lambda s t d} \approx 0.989+/-0.004\right)$ was used for baseline measurements. The experimental setup for the spectral, directional-hemispherical reflectivity measurements are illustrated in Figure 4. Orienting the beam as shown in Figure 4 ensures that specular reflections are captured within the sphere.

Like Eq. (2), dark current effects were subtracted from the reflectivity measurements in Eq. (3). The numerator in this equation is comprised of current measurements when the sample was mounted as shown in Figure 4B, whereas the denominator contains current measurements when the calibration standard was mounted as shown in Figure 4A. The reflectivity of the calibration standard is represented by $\rho_{\lambda s t d}$. As previously explained, the spectral, normalnormal reflectivity used to calculate the spectral absorption coefficient was approximated by using the spectral, directional-hemispherical reflectivity measurements.

$$
\rho_{\lambda}^{\perp \perp} \approx \rho_{\lambda}^{\prime \ominus}=\frac{\left(\mathrm{I}_{\mathrm{m}}-\mathrm{I}_{\mathrm{d}}\right)_{\mathrm{s}}}{\left(\mathrm{I}_{\mathrm{m}}-\mathrm{I}_{\mathrm{d}}\right)_{\mathrm{c}}} * \rho_{\lambda \mathrm{std}}
$$




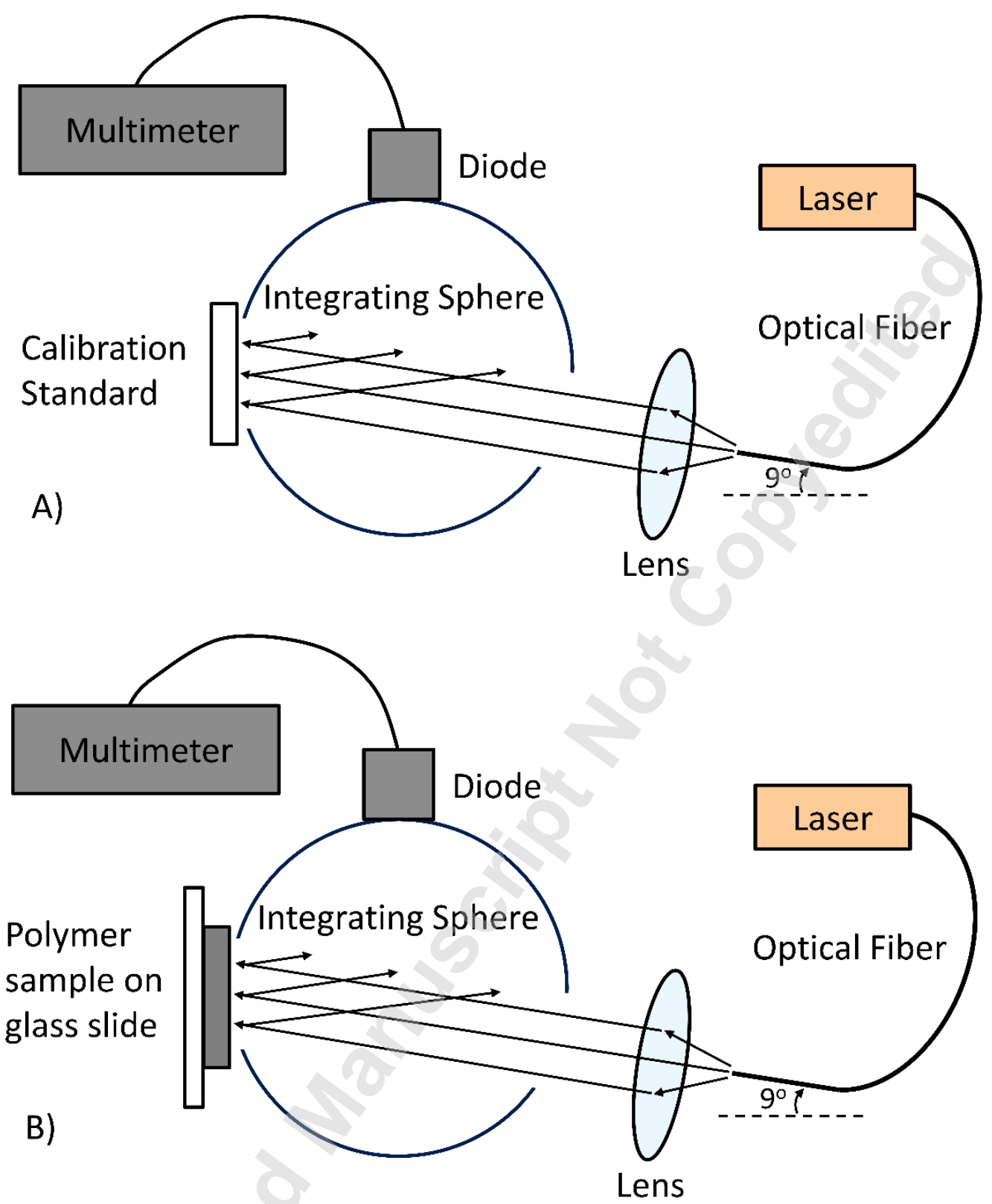

Figure 4: Process for spectral, directional-hemispherical reflectivity measurements using an integrating sphere. A) Radiation enters the sphere unobstructed and is partially reflected off a calibration standard, while the resulting diode detector current is measured. B) The calibration standard is replaced with a sample and the process is repeated.

\section{Thickness and Density Measurements}

Sample thickness was measured using an analog micrometer with a $1.3 \mu \mathrm{m}$ resolution.

Three measurements were averaged together at randomly selected locations around the 
midpoint of the sample to obtain the reported thicknesses shown in Table 3 in the results section.

Sample density was determined using Archimedes' principle by measuring the sample weight before and after submersion in Isopropanol with a scale that has a resolution of 0.0002 grams. The exact process is described thoroughly in the literature [19]. Sample densities are tabulated with the spectral absorption coefficients of the partially dense samples in Table 3.

\section{Uncertainty Analysis}

Uncertainty estimations for the sample thickness, transmissivity, and reflectivity measurements were combined together to obtain the uncertainties of the spectral absorption coefficient calculations. As explained previously, three thickness measurements were averaged together for each sample. The standard deviation of these three measurements was multiplied by the $95 \%$, two-tailed, student $t$ table value to estimate the uncertainties of the averaged sample thickness measurements, $U_{t}$.

The uncertainties of the transmissivity measurements, $U_{\tau}$, were estimated using Eq. (4):

$$
\mathrm{U}_{\tau}=\left[\left(\frac{\partial \tau_{\lambda}^{\perp}}{\partial \mathrm{I}_{\mathrm{m}, \mathrm{s}}} * \mathrm{U}_{\mathrm{I}, \mathrm{m}, \mathrm{s}}\right)^{2}+\left(\frac{\partial \tau_{\lambda}^{\perp^{\circ}}}{\partial \mathrm{I}_{\mathrm{d}, \mathrm{s}}} * \mathrm{U}_{\mathrm{I}, \mathrm{d}, \mathrm{s}}\right)^{2}+\left(\frac{\partial \tau_{\lambda}^{\perp}}{\partial \mathrm{I}_{\mathrm{m}, \mathrm{e}}} * \mathrm{U}_{\mathrm{I}, \mathrm{m}, \mathrm{e}}\right)^{2}+\left(\frac{\partial \tau_{\lambda}^{\perp}}{\partial \mathrm{I}_{\mathrm{d}, \mathrm{e}}} * \mathrm{U}_{\mathrm{I}, \mathrm{d}, \mathrm{e}}\right)^{2}\right]^{\frac{1}{2}}
$$

where $U_{1}$ is the uncertainty of the current measured from a photodiode using a multimeter for the four different configurations indicated by subscripts $m, d, s$, and e found in Eq. (2). For each configuration, $U_{1}$ was found using Eq. (5):

$$
\mathrm{U}_{\mathrm{I}}=\sqrt{\mathrm{U}_{\mathrm{o}}^{2}+\mathrm{U}_{\mathrm{i}}^{2}+\mathrm{U}_{\text {noise }}^{2}}
$$


where $U_{o}$ is the resolution of the multimeter and was equal to $1 \mathrm{nA}$. $U_{\text {noise }}$ is uncertainty due to measurement noise and was estimated as follows. For each current measurement described in Eq. (2), 30 samples were taken. The standard deviation between these samples was multiplied by the $95 \%$, two-tailed, student $t$ table value to obtain $U_{\text {noise. }} U_{i}$ is the instrument uncertainty and was defined by Eq. (6):

$$
\mathrm{U}_{\mathrm{i}}= \pm \mathrm{t}_{\mathrm{v}, 95} * \mathrm{~S}_{\mathrm{xy}}
$$

where $S_{x y}$ is the standard error of the instrument calibration curve. A linear calibration curve was found by measuring the current output of the photodiode as a function of the input laser power. The standard error was multiplied by the $95 \%$, two-tailed, student $t$ table value to obtain an instrument uncertainty of $U_{i}=+/-8.857 n A$.

The uncertainties of the reflectivity measurements, $U_{\rho}$, were estimated using Eq. (7):

$$
\begin{aligned}
& \mathrm{U}_{\rho}=\left[\left(\frac{\partial \rho_{\lambda}^{\prime}}{\partial \mathrm{I}_{\mathrm{m}, \mathrm{s}}} * \mathrm{U}_{\mathrm{I}, \mathrm{m}, \mathrm{s}}\right)^{2}+\left(\frac{\partial \rho_{\lambda}^{\prime}}{\partial \mathrm{I}_{\mathrm{d}, \mathrm{s}}} * \mathrm{U}_{\mathrm{I}, \mathrm{d}, \mathrm{s}}\right)^{2}+\left(\frac{\partial \rho_{\lambda}^{\prime}}{\partial \mathrm{I}_{\mathrm{m}, \mathrm{c}}} * \mathrm{U}_{\mathrm{I}, \mathrm{m}, \mathrm{c}}\right)^{2}+\left(\frac{\partial \rho_{\lambda}^{\prime}}{\partial \mathrm{I}_{\mathrm{d}, \mathrm{c}}} * \mathrm{U}_{\mathrm{I}, \mathrm{d}, \mathrm{c}}\right)^{2}\right. \\
& \left.+\left(\frac{\partial \rho_{\lambda}^{\prime}}{\partial \rho_{\lambda s t d}} * U_{\mathrm{Rstd}}\right)^{2}\right]^{\frac{1}{2}}
\end{aligned}
$$

where $U_{1}$ is the uncertainty of the current measured from a photodiode using a multimeter for the four different configurations indicated by subscripts $m, d, s$, and c found in Eq. (3). U Ustd is the uncertainty of the calibrated reflectance standard and is tabulated by the manufacturer as a function of the wavelength of incident irradiation and the reflectivity of the sample being measured. The range of $U_{R s t d}$ used in in this project was between 0.0022 and 0.0064 . 
The preceding uncertainty estimations were combined in Eq. (8) to obtain the uncertainties of the spectral absorption coefficient calculations, $U_{\kappa}$, for each sample individually.

$$
\mathrm{U}_{\kappa}=\sqrt{\left(\frac{\partial \kappa_{\lambda}}{\partial \rho_{\lambda}^{\perp \perp}} * \mathrm{U}_{\rho}\right)^{2}+\left(\frac{\partial \kappa_{\lambda}}{\partial \tau_{\lambda}^{\perp \perp}} * \mathrm{U}_{\tau}\right)^{2}+\left(\frac{\partial \kappa_{\lambda}}{\partial \mathrm{t}} * \mathrm{U}_{\mathrm{t}}\right)^{2}}
$$

Eq. (9) was used to estimate the uncertainty associated with averaging multiple spectral absorption coefficient calculations together:

$$
\overline{\mathrm{U}_{\mathrm{\kappa}}}=2\left[\mathrm{U}_{\mathrm{\kappa o}}^{2}+\left(\frac{\mathrm{S}_{\mathrm{x}}}{\sqrt{\mathrm{m}}}\right)^{2}\right]^{\frac{1}{2}}
$$

where $S_{x}$ is the standard deviation between spectral absorption coefficient calculations from different samples of the same material, and $\mathrm{m}$ is the number of samples whose spectral absorption coefficients are being averaged together. $\bigcup_{\text {ко }}$ is an uncertainty estimation using averaged inputs as shown in Eq. (10):

$$
\mathrm{U}_{\kappa o}=\sqrt{\left(\frac{\partial \overline{\kappa_{\lambda}}}{\partial \overline{\rho_{\lambda}^{\perp \perp}}} * \overline{\mathrm{U}_{\rho}}\right)^{2}+\left(\frac{\partial \overline{\kappa_{\lambda}}}{\partial \overline{\tau_{\lambda}^{\perp \perp}}} * \overline{\mathrm{U}_{\tau}}\right)^{2}+\left(\frac{\partial \overline{\kappa_{\lambda}}}{\partial \overline{\mathrm{t}}} * \overline{\mathrm{U}_{\mathrm{t}}}\right)^{2}}
$$

where $\overline{\rho_{\lambda}^{\perp \perp}}$ is the spectral, normal-normal reflectivity averaged between multiple samples of the same material, $\overline{\tau_{\lambda}^{\perp \perp}}$ is the spectral, normal-normal transmissivity averaged between multiple samples of the same material, $\bar{t}$ is the thickness averaged between multiple samples of the same material, and $\bar{U}$ is the averaged uncertainty of the reflectivity, transmissivity, or thickness measurements indicated by subscripts $\rho, \tau$, and $t . \overline{\kappa_{\lambda}}$ was defined by Eq. (11): 


$$
\overline{\kappa_{\lambda}}=\frac{\ln \left(\frac{\left(1-\overline{\rho_{\lambda}^{\perp \perp}}\right)}{\overline{\tau_{\lambda}^{\perp \perp}}}\right)}{\overline{\mathrm{t}}}
$$

\section{Justification of Assumptions and Simplifications}

The system was said to be non-scattering when deriving Eqs. (1), (2), and (3). This simplification is consistent with the models used in the literature [2-3,5-9]. Although some scattering will occur, the measurements and calculations presented in this paper do not consider scattering effects. Further investigation is needed to understand how additively manufactured polymer parts scatter radiation.

It was assumed that the spectral, normal-normal reflectivity used to calculate the spectral absorption coefficient could be approximated with the spectral, directionalhemispherical reflectivity measurements from the integrating sphere system. This assumption was validated by comparing measurements taken with the integrating sphere system to spectral, normal-normal reflectivity calculations using the Fresnel equation and reported indices of refraction $[15,17]$. As shown in Table 1, the difference between the spectral, directional-hemispherical measurements and the range of spectral, normal-normal reflectivity calculations was less than 0.01. Assumptions and approximations used in this paper regarding internal reflections and reflectivity measurements will need to be altered when analyzing highly reflective (white) AM polymers. 
Table 1: Comparing spectral, directional-hemispherical reflectivity measurements from an integrating sphere system to spectral, normal-normal reflectivity calculations from Fresnel's equation

\begin{tabular}{cccc}
\hline Material & $\begin{array}{c}\text { Index of Refraction } \\
{[17]}\end{array}$ & $\begin{array}{c}\boldsymbol{\rho}_{\lambda}{ }^{\Perp 1} \text { Calculated Using } \\
\text { Fresnel Equation [15] }\end{array}$ & $\begin{array}{c}\boldsymbol{\rho}_{\lambda}{ }^{\prime} \circ \text { Measured with the } \\
\text { Integrating Sphere }\end{array}$ \\
\hline PLA & $1.35-1.45$ & $0.022-0.034$ & 0.039 \\
ABS & 1.54 & 0.045 & 0.052 \\
Polyamide 12 & $1.52-1.53$ & $0.043-0.044$ & 0.037
\end{tabular}

Reflections at the polymer-glass interface (interface 2 in Figure 2) were neglected because of the similar indices of refraction. PLA, ABS, and Polyamide 12 have refractive indices of about $1.35-1.45,1.54$, and $1.52-1.53$, whereas the borosilicate glass has a refractive index of about $1.5[17,18]$.

Reflections at the glass-air interface (interface 3 in Figure 2) were also neglected. Based on the spectral absorption coefficients measured in this project, transmittance through a sample was $24 \%$ at most, and reflectance off a glass slide was $8 \%$ at most. Using these values, it can be shown that less than one percent of the spectral intensity incident on the left surface in Figure 2 would transmit through the polymer-glass sample, reflect off the glass-air interface (interface 3), and transmit back through the sample to the left through interface 1 . Therefore, it was assumed that the spectral, normal-normal reflectivity of the polymer-glass combination was equivalent to the spectral, normal-normal reflectivity of the polymer used in the spectral absorption coefficient calculations. This assumption would not be valid if the samples were highly transparent.

\section{Sample Creation}

Partially and fully dense samples were created from black ABS, PLA, and Polyamide 12. The fully dense samples were created using two different methods. Some were created by TSEA-20-1503 Wallace et al. 14 
melting material on one-millimeter thick glass slides in an oven, while a weight (either 10 or 20 pounds) rested on their surface. Representative samples are shown in Figure 5. Other fully dense samples were created using a LECO PR-32 heated hydraulic press. The samples created using the hydraulic press were not fused to glass slides. However, Eq. (1) was still used to calculate the spectral absorption coefficient of these samples by increasing the value of the transmissivity of the glass slide in the equation to a value of one $\left(\tau_{\lambda \mathrm{g}}^{\perp \perp}=1\right)$.

To verify that the different manufacturing methods did not impact the spectral absorption coefficient calculations, several fully dense PLA samples were created using either the heated hydraulic press or the oven and weight. The calculated spectral absorption coefficients of these two different sets of samples differed by less than $0.0008 \mu \mathrm{m}^{-1}$. Therefore, any variations due to differences in the manufacturing process were considered negligible.

The partially dense PLA and ABS samples were created using a CreatorPro FlashForge 3D printer set at full infill density. The black PLA filament was purchased from Hatchbox, while the black ABS filament was purchased from IC3D. These 50 by $25 \mathrm{~mm}$ samples had various thicknesses based on the number of layers deposited during manufacturing as shown in Table 3. The partially dense Polyamide 12 samples were created using a large area projection sintering (LAPS) system [12,13]. These 15 by $20 \mathrm{~mm}$ samples were created from PA2202 black Polyamide 12 powder purchased from EOS. None of the partially dense samples were fused to glass slides, therefore, the transmissivity of the glass slide used in Eq. (1) was set equal to one when calculating their spectral absorption coefficients. 


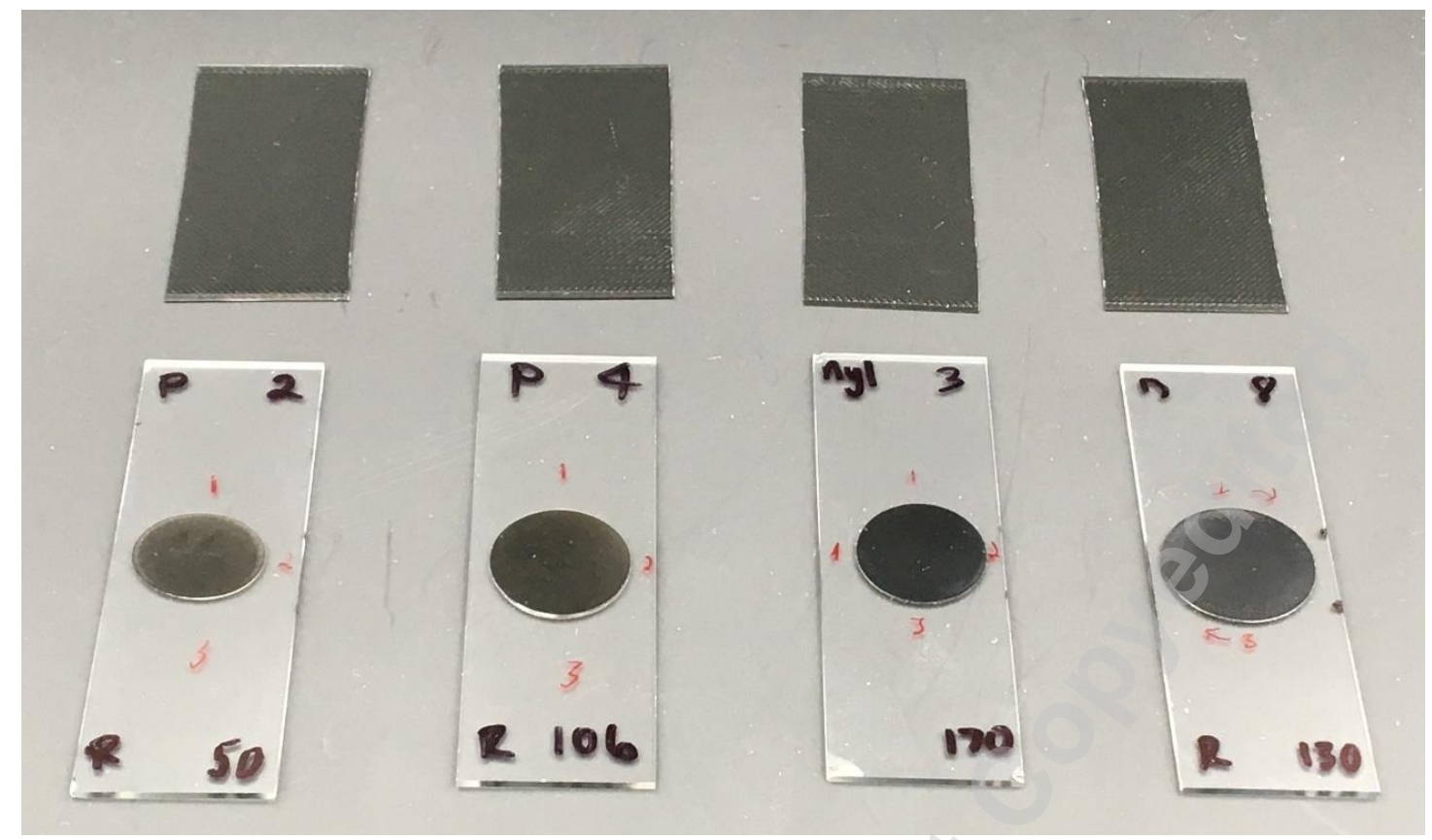

Figure 5: Partially dense ABS (top) and fully dense PLA and Polyamide 12 (bottom) samples

\section{Projector Spectrum Measurement}

As mentioned in the introduction, the literature utilizes existing equipment (including a modified projector with a metal halide bulb) for both sintering material and performing active thermography. For this purpose, the spectrum of the X316 Optoma Projector was measured using a spectrometer [20]. The projector was previously modified for use in Large Area Projection Sintering (LAPS) $[12,13]$. Figure 6 shows the measured spectrum, which has been normalized. The uncertainty envelope was determined by taking 100 samples at each wavelength over the spectrum and multiplying the standard deviation between these measurements by the $95 \%$, two tailed, student $t$ table value. The maximum of these calculated values was designated as the uncertainty of the system. 


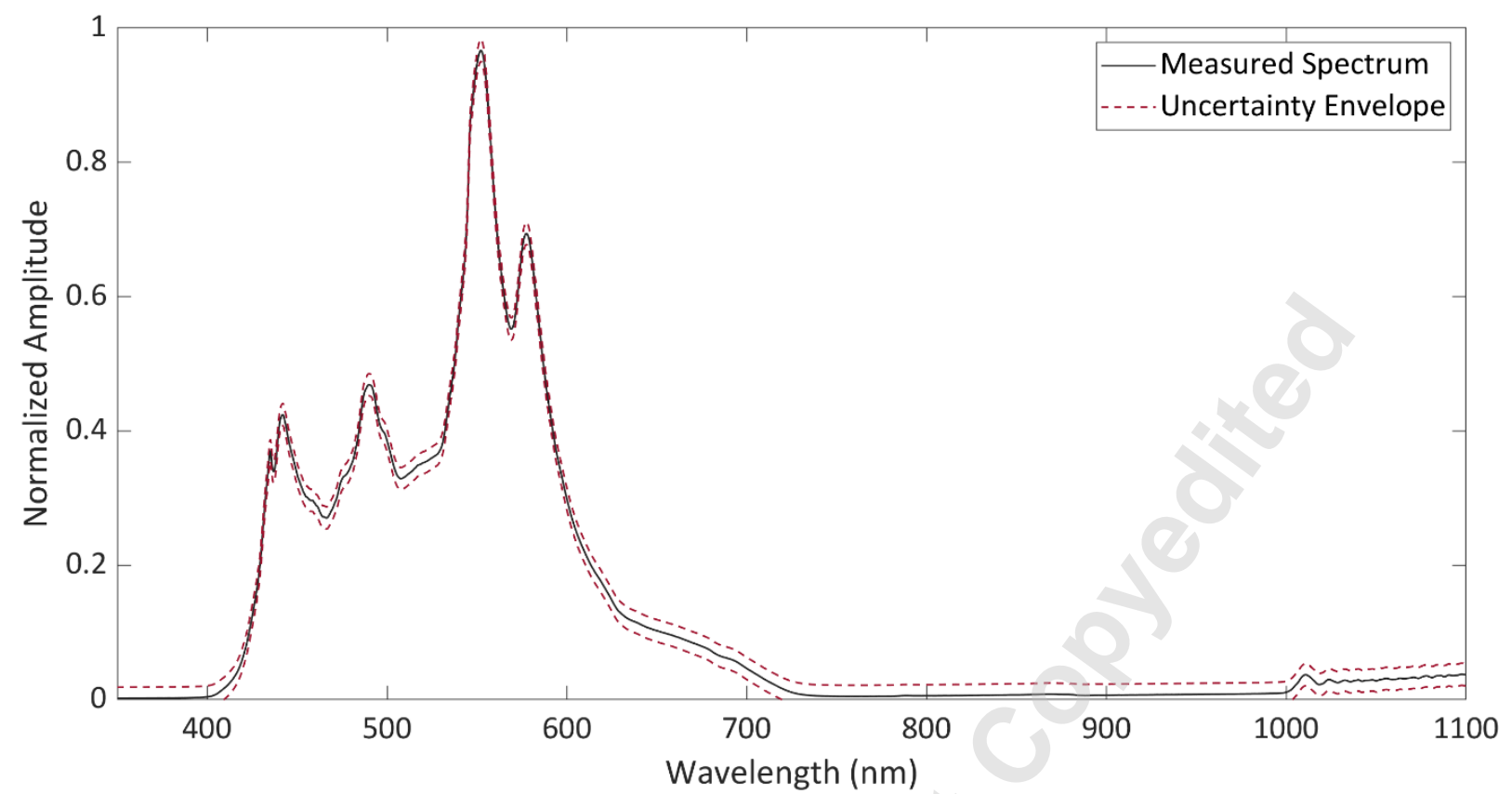

Figure 6: Measured spectrum of the X316 Optoma Projector

\section{RESULTS}

Measurements and Calculations

Spectral absorption coefficients of PLA, ABS and Polyamide 12 at $532 \mathrm{~nm}, 660 \mathrm{~nm}$, and over the entire spectrum shown in Figure 6 are presented in Tables 2 and 3.

Table 2: Absorption coefficient of fully dense AM polymers $\left(\mu \mathrm{m}^{-1}\right)$

\begin{tabular}{cccccc}
\hline Material & Color & Manufacturer & $\mathbf{6 6 0} \mathbf{n m}$ & $\mathbf{5 3 2} \mathbf{~ n m}$ & Projector Spectrum \\
\hline PLA & Black & Hatchbox & $0.022+/-0.002$ & $0.026+/-0.003$ & $0.023+/-0.01$ \\
ABS & Black & IC3D & $0.025+/-0.003$ & $0.028+/-0.005$ & $0.025+/-0.02$ \\
Polyamide 12 & Black & EOS & $0.026+/-0.003$ & $0.030+/-0.005$ & $0.023+/-0.02$
\end{tabular}


Table 3: Absorption coefficient of partially dense AM polymers $\left(\mu \mathrm{m}^{-1}\right)$. The Black ABS, PLA, and Polyamide 12 materials were purchased from IC3D, Hatchbox, and EOS respectively. FFF was used to create the ABS and PLA samples, whereas LAPS was used to create the Polyamide 12 samples.

\begin{tabular}{|c|c|c|c|}
\hline \multicolumn{4}{|c|}{ ABS } \\
\hline Number of layers printed & 2 & 3 & 4 \\
\hline Thickness ( $\mu m)$ & $206+/-3$ & $297+/-6$ & $418+/-3$ \\
\hline Density $\left(\mathrm{Kg} / \mathrm{m}^{3}\right)$ & 1083 & 1077 & 1080 \\
\hline$\kappa_{\lambda}$ at $532 \mathrm{~nm}\left(\mu \mathrm{m}^{-1}\right)$ & $0.021+/-0.001$ & $0.027+/-0.004$ & $0.022+/-0.01$ \\
\hline$\kappa_{\lambda}$ at $660 \mathrm{~nm}\left(\mu \mathrm{m}^{-1}\right)$ & $0.018+/-0.001$ & $0.023+/-0.004$ & $0.020+/-0.01$ \\
\hline$\kappa_{\lambda}$ over projector spectrum $\left(\mu m^{-1}\right)$ & $0.021+/-0.03$ & $-\quad \Delta$ & $0.014+/-0.07$ \\
\hline \multicolumn{4}{|c|}{ PLA } \\
\hline Number of layers printed & 2 & 3 & 4 \\
\hline Thickness ( $\mu m)$ & $189+/-3$ & $268+/-7$ & $361+/-3$ \\
\hline Density $\left(\mathrm{Kg} / \mathrm{m}^{3}\right)$ & 1289 & 1289 & 1291 \\
\hline$\kappa_{\lambda}$ at $532 \mathrm{~nm}\left(\mu \mathrm{m}^{-1}\right)$ & $0.026+/-0.003$ & $0.028+/ 0.003$ & $0.025+/-0.01$ \\
\hline$\kappa_{\lambda}$ at $660 \mathrm{~nm}\left(\mu \mathrm{m}^{-1}\right)$ & $0.021+/-0.001$ & $0.022+/-0.002$ & $0.020+/-0.01$ \\
\hline$\kappa_{\lambda}$ over projector spectrum $\left(\mu m^{-1}\right)$ & $0.023+/-0.03$ & - & - \\
\hline \multicolumn{4}{|c|}{ POLYAMIDE 12} \\
\hline Number of layers printed & 2 & 2 & 3 \\
\hline Thickness ( $\mu m)$ & $154+/-12$ & $155+/-6$ & $239+/-4$ \\
\hline Density $\left(\mathrm{Kg} / \mathrm{m}^{3}\right)$ & 1065 & 1054 & 1065 \\
\hline$\kappa_{\lambda}$ at $532 \mathrm{~nm}\left(\mu \mathrm{m}^{-1}\right)$ & $0.025+/-0.003$ & $0.024+/-0.002$ & $0.024+/-0.007$ \\
\hline$\kappa_{\lambda}$ at $660 \mathrm{~nm}\left(\mu \mathrm{m}^{-1}\right)$ & $0.022+/-0.002$ & $0.020+/-0.001$ & $0.022+/-0.003$ \\
\hline$\kappa_{\lambda}$ over projector spectrum $\left(\mu m^{-1}\right)$ & $0.019+/-0.009$ & $0.017+/-0.007$ & $0.016+/-0.016$ \\
\hline
\end{tabular}

\section{Validation}

The reflectivity measurements were validated as shown in Table 1, using Fresnel's equation [15]. The transmissivity measurement process was validated by comparing measurements from the integrating sphere system to measurements from a Cary-60 spectrophotometer. This spectrophotometer was designed to measure the absorptance of 
liquid solutions but was modified to hold and measure the transmissivity of one PLA sample.

The integrating sphere system was also modified to replicate the geometric configuration of the spectrophotometer. Figure 7 illustrates how these two measurement systems validate each other.

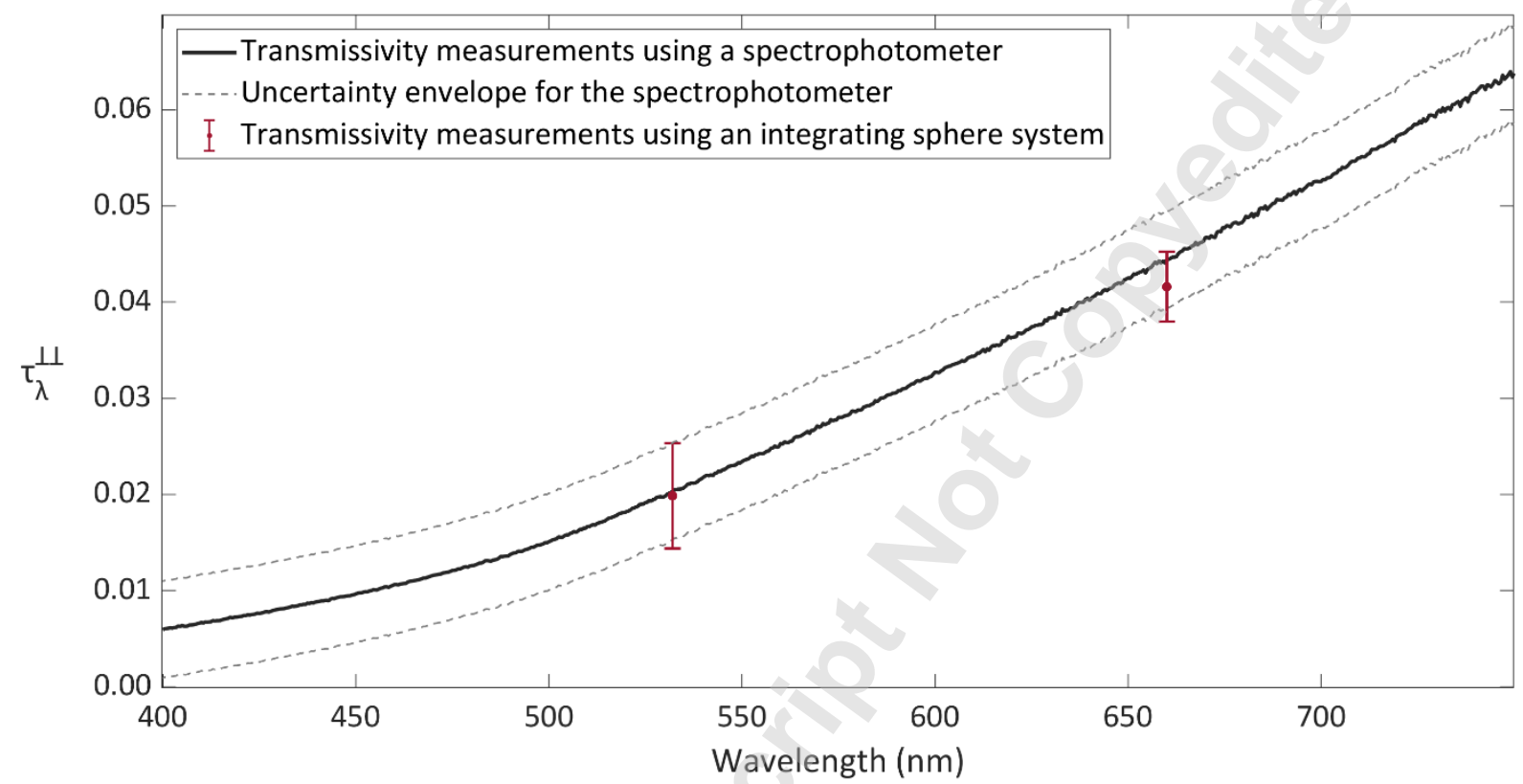

Figure 7: Comparing spectral, normal-normal transmissivity measurements obtained using a spectrophotometer and an integrating sphere for a black, fully dense, $109 \mu \mathrm{m}$ thick, PLA sample fused to a glass slide

Figures 8 illustrates the accuracy of the calculated absorption coefficients in predicting transmission. Exponential curves based on Beer's Law [15] and the calculated absorption coefficients were plotted next to the spectral, normal-hemispherical transmissivities measured with the integrating sphere system. The exponential curves fit the transmission data well. 
Copyright (C) 20ASME Jourral of Thermal Science and Engineering Applications

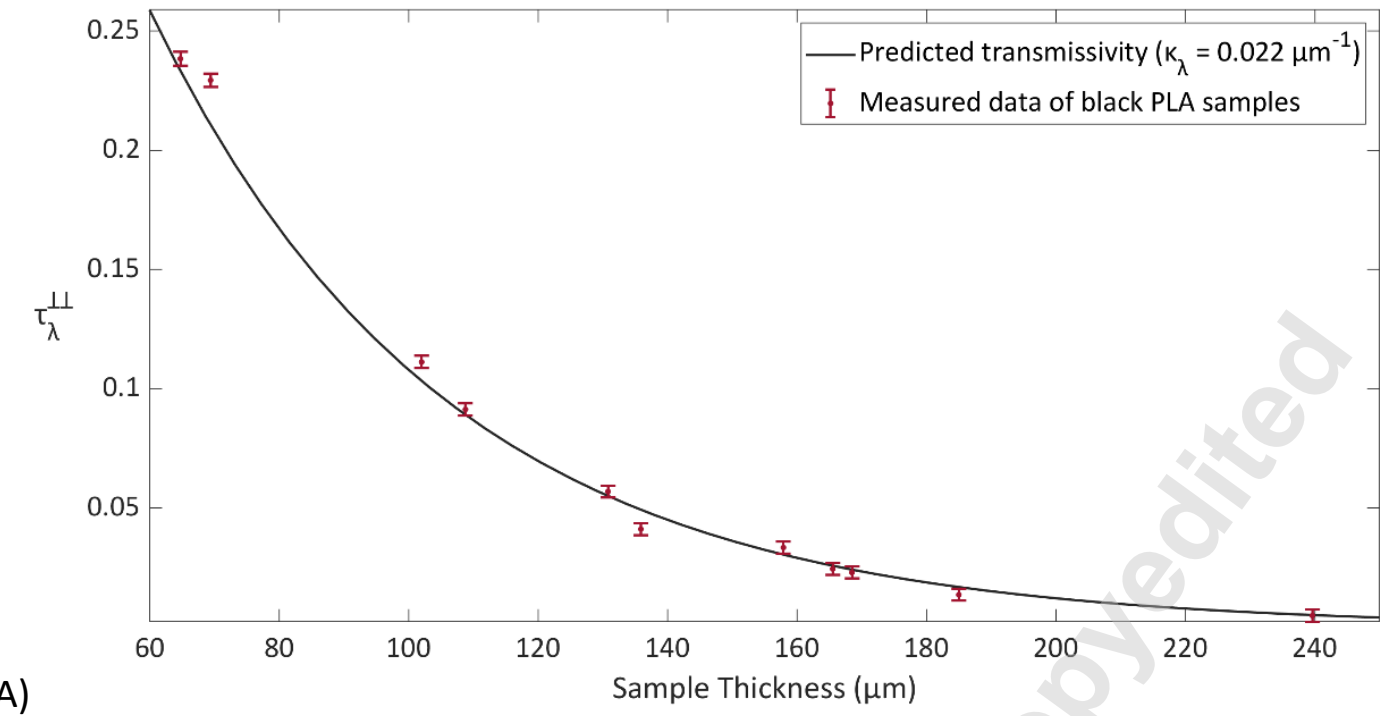

A)

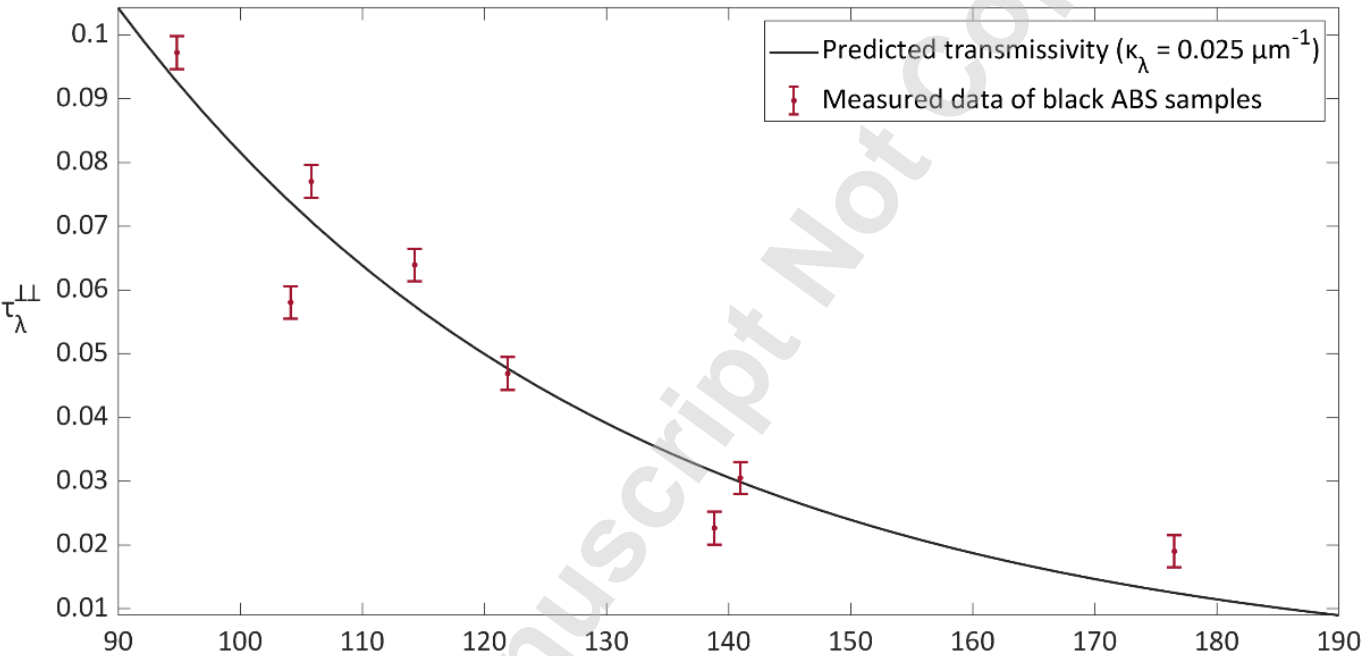

B)

Sample Thickness $(\mu \mathrm{m})$

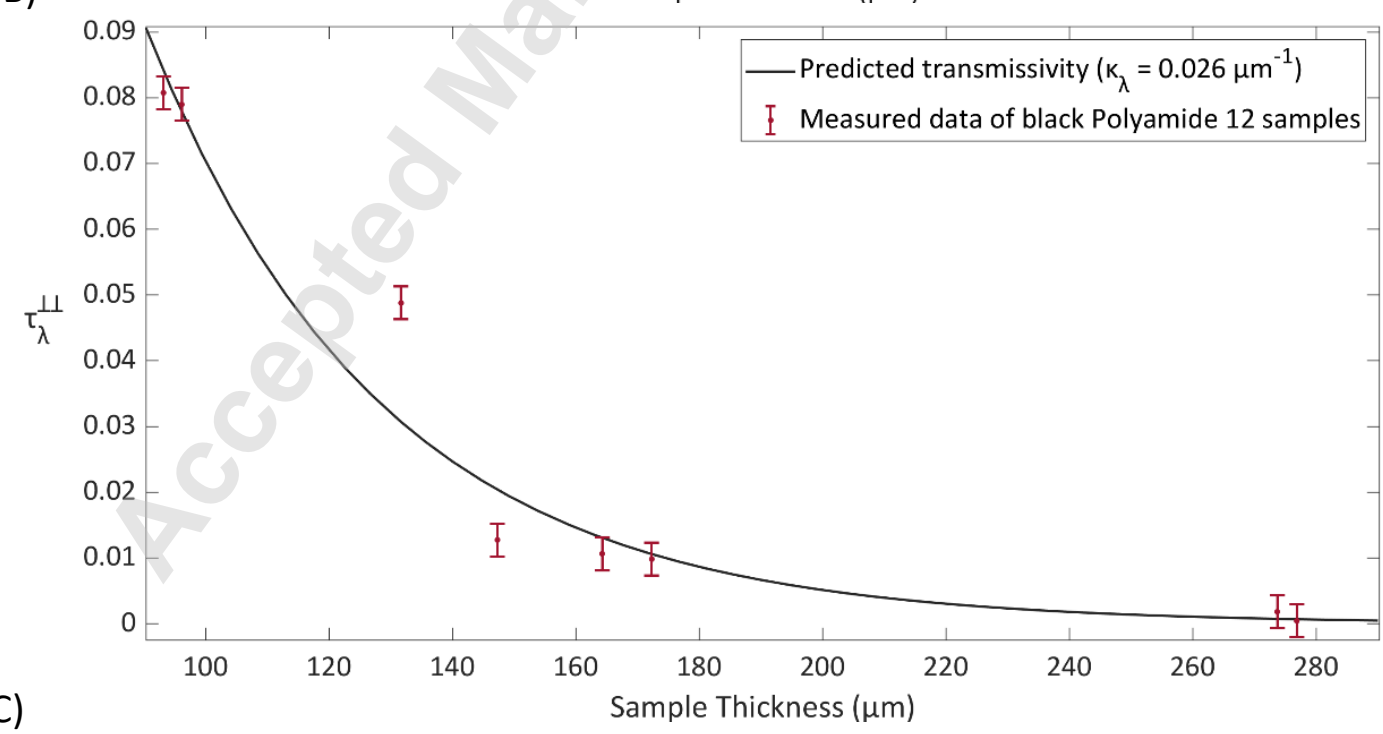

Figure 8: Transmissivity of black, fully dense PLA (A), ABS (B) and Polyamide 12 (C) samples fused to glass slides, irradiated at $660 \mathrm{~nm}$ 


\section{CONCLUSIONS}

Spectral absorption coefficient calculations and uncertainty estimations have been presented for black PLA, ABS, and Polyamide 12 samples. The reflectivity measurements used in the absorption coefficient calculations were validated using Fresnel's equation. The transmissivity measurements used in the absorption coefficient calculations have been validated by comparing results obtained from a system based on an integrating sphere, and a spectrophotometer.

While the data reveals that PLA is most sensitive to effects from in-depth absorption, all three polymers have measured spectral absorption coefficients in the visible spectrum between 0.02 and $0.03 \mu \mathrm{m}^{-1}$. At a depth of $96 \mu \mathrm{m}$, approximately $90 \%$ of irradiation in the visible spectrum incident on the surface of a PLA part is absorbed. If a defect is present at this depth, it is likely that a significant portion of the remaining irradiation will be transmitted through the defect and into the material below. In parts made with ABS and Polyamide 12 , the depth at which $90 \%$ of the irradiation is absorbed decreases from 96 to 87 and $82 \mu \mathrm{m}$ respectively. Transmission through subsurface defects will distort surface temperatures necessary for active thermography measurements. Thermographic models should include effects from in-depth absorption when analyzing defects in AM polymers less than 100 microns below the surface of the part.

These results also have important implications for sintering materials with radiation in the visible spectrum. The absorption depths mentioned in the previous paragraph are significant relative to typical layer thickness of many AM processes ( $\sim 50-100 \mu \mathrm{m})$. Traditionally, powder-bed fusion AM processes have used infrared radiation from $\mathrm{CO}_{2}$ lasers to sinter 
material. However, using radiation in the visible spectrum would result in different absorption profiles which may contribute to differences in the properties of the resulting parts [12].

Future work is needed to extend these measurements to different AM materials, colored filaments, and spectral regions. Assumptions and approximations used in this paper regarding internal reflections and reflectivity measurements will need to be altered when analyzing white AM polymers. Understanding the spectral absorption of AM materials will give researchers and developers the necessary tools to improve AM processes that utilize radiative heat transfer to sinter powders. In addition, accurate spectral absorption coefficient measurements are necessary to successfully adapt active thermography techniques as a nondestructive, non-contact means of in-situ monitoring of AM processes.

\section{ACKNOWLEDGMENT}

We would like to thank Trevor Boardman for providing the partially dense ABS and PLA samples, as well as Spencer Abbot for creating the partially dense Polyamide 12 samples. In addition, we would like to acknowledge Dr. William G. Pitt for providing the spectrophotometer and Dr. Troy Munro for providing the lasers and spectrometer used to perform these measurements. Finally, we would like to acknowledge Chandler Warr and Derek Sanchez for their assistance in experimental setup.

\section{FUNDING}

This research was funded in part by the Utah NASA Space Grant Consortium, NASA Grant \#NNX15AI24H, and by the National Science Foundation through award CMMI- 1851728. 
NOMENCLATURE

\begin{tabular}{|c|c|}
\hline AM & additive manufacturing \\
\hline FFF & fused filament fabrication \\
\hline LAPS & large area projection sintering \\
\hline $\mathrm{cp}$ & specific heat capacity \\
\hline h & coefficient of convection \\
\hline k & thermal conductivity \\
\hline $\mathrm{I}_{\lambda}$ & spectral intensity \\
\hline $\mathrm{I}_{\lambda \mathrm{o}}$ & incident spectral intensity; $\left(\mathrm{I}_{\lambda}(0)\right)$ \\
\hline$I_{d}$ & current measured from the photodiode when the radiation source was off \\
\hline $\mathrm{I}_{\mathrm{m}}$ & current measured from the photodiode when the radiation source was on \\
\hline $\mathrm{m}$ & number of measurements averaged together \\
\hline s & distance into the sample from its surface in the direction of the irradiation \\
\hline 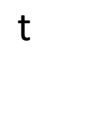 & sample thickness; $\left(t_{p}+t_{g}\right)$ \\
\hline$t_{p}$ & thickness of the polymer sample \\
\hline$t_{g}$ & thickness of the glass slide \\
\hline$t_{\mathrm{v}, 95}$ & $95 \%$, two-tailed, student t table value \\
\hline & thickness measurements averaged between multiple samples \\
\hline
\end{tabular}




\begin{tabular}{|c|c|}
\hline $\mathrm{S}_{\mathrm{X}}$ & standard deviation \\
\hline$S_{x y}$ & standard error of the instrument calibration curve \\
\hline $\mathrm{U}$ & measurement uncertainty \\
\hline $\mathrm{U}_{\mathrm{i}}$ & instrument uncertainty \\
\hline $\mathrm{U}_{\mathrm{I}}$ & uncertainty of the current measured from the photodiode \\
\hline $\mathrm{U}_{\mathrm{o}}$ & resolution of the multimeter used to measure current \\
\hline $\mathrm{U}_{\text {ко }}$ & uncertainty estimation using averaged inputs \\
\hline $\mathrm{U}_{\text {noise }}$ & uncertainty due to measurement noise \\
\hline$\overline{\mathrm{U}}$ & measurement uncertainty averaged between multiple samples \\
\hline$\kappa_{\lambda}$ & spectral absorption coefficient \\
\hline$\kappa_{\lambda p}$ & spectral absorption coefficient of the polymer sample \\
\hline$\kappa_{\lambda g}$ & spectral absorption coefficient of the glass slide \\
\hline$\overline{\kappa_{\lambda}}$ & spectral absorption coefficient averaged between multiple samples \\
\hline$\rho$ & density \\
\hline$\rho_{\lambda \text { std }}$ & spectral reflectivity of the calibration standard \\
\hline$\rho_{\lambda}^{\perp \perp}$ & spectral, normal-normal reflectivity \\
\hline$\rho_{\lambda}^{\prime \bullet}$ & spectral, directional-hemispherical reflectivity \\
\hline$\rho_{\lambda \mathrm{p}}^{\perp \perp}$ & spectral, normal-normal reflectivity of the polymer sample \\
\hline
\end{tabular}


$\begin{array}{ll}\rho_{\lambda \text { gp }}^{\perp \perp} & \text { spectral, normal-normal reflectivity of the polymer-glass combination } \\ \overline{\rho_{\lambda}^{\perp \perp}} & \text { spectral, normal-normal reflectivity averaged between multiple samples } \\ \tau_{\lambda}^{\perp \perp} & \text { spectral, normal-normal transmissivity } \\ \tau_{\lambda}^{\perp \rho} & \text { spectral, normal-hemispherical transmissivity } \\ \tau_{\lambda \mathrm{g}}^{\perp \perp} & \text { spectral, normal-normal transmissivity of glass slide } \\ \tau_{\lambda \mathrm{p}}^{\perp \perp} & \text { spectral, normal-normal transmissivity of polymer sample } \\ \tau_{\lambda \mathrm{gp}}^{\perp \perp} & \text { spectral, normal-normal transmissivity of polymer-glass combination } \\ \overline{\tau_{\lambda}^{\perp \perp}} & \text { spectral, normal-normal transmissivity averaged between multiple samples }\end{array}$

\section{SUBSCRIPTS}

C

e

$S$ current measured from the photodiode when radiation entered the integrating sphere and a calibration standard was mounted as shown in Figure 4A current measured from the photodiode when radiation entered the integrating sphere unobstructed as shown in Figure $3 \mathrm{~A}$ current measured from the photodiode when radiation entered the integrating sphere and a sample was mounted as shown in either Figure 3B or Figure 4B 


\section{REFERENCES}

[1] Yao, B., Imani, F., Sakpal, A. S., Reutzel, E. W., and Yang, H., 2018, "Multifractal Analysis of Image Profiles for the Characterization and Detection of Defects in Additive Manufacturing," ASME J. Manuf. Sci. E., 140(3), p. 031014. https://doi.org/10.1115/1.4037891

[2] Pierce, J., and Crane, N. B., 2019, "Impact of Pulse Length on the Accuracy of Defect Depth Measurements in Pulse Thermography," ASME. J. Heat Transfer, 141(4), p. 042002. https://doi.org/10.1115/1.4042785

[3] Pierce, J.R., and N.B. Crane.,2017, "Preliminary Nondestructive Testing Analysis on 3D Printed Structure Using Pulsed Thermography," Proceedings of the ASME 2017 International Mechanical Engineering Congress and Exposition, 8. https://doi.org/10.1115/IMECE201771935

[4] Metz, C., Franz, P., Fischer, C., Wachtendorf, V., and Maierhofer, C., 2019, "Active Thermography for Quality Assurance of 3D-Printed Polymer Structures," Quantitative InfraRed Thermography Journal. https://doi.org/10.1080/17686733.2019.1686896

[5] Almond, D., and Pickering, S., 2012, "An Analytical Study of the Pulsed Thermography Defect Detection Limit," Journal of Applied Physics, 111(9): p. 093510. https://doi.org /10.1063/1.362662

[6] Ringermacher H., Archacki, R., and Veronesi, W., 1998, "Nondestructive Testing: Transient Depth Thermography," U.S. Patent No. 5,711,603

[7] Maldague X., and Marinetti, S., 1996, "Pulse Phase Infrared Thermography," Journal of Applied Physics, 79(5), pp. 2694-2698. https://doi.org/10.1063/1.362662

[8] Busse G., Wu, D., and Karpen, W., 1992, "Thermal Wave Imaging with Phase Sensitive Modulated Thermography," Journal of Applied Physics, 71(8), pp. 3962-3965. https://doi.org/10.1063/1.351366

[9] Bernegger, R., Altenburg, S. J., and Maierhofer, C., 2020, "Quantifcation of Delaminations in Semitransparent Solids Using Pulsed Thermography and Mathematical 1D Models, " Int. J. of Thermophysics, 41(67). https://doi.org/10.1007/s10765-020-02642-7

[10] Barzic, A.I., and Barzic, R.F., 2015, “Optical Properties of Polysaccharide/Polylactide Blends," U.P.B. Sci. Bull., 77(4), pp. 293-302. https://www.scientificbulletin.upb.ro /rev_docs_arhiva/fulldfa_372604.pdf

[11] Squire, A. D., and Lewis, R. A., 2017, "Mechanical and Optical Viability of Eighteen Filaments for 3D Printing of Terahertz Components," Proceedings of the 42nd International Conference on Infrared, Millimeter, and Terahertz Waves, Cancun, MX, August 27, 2017, pp. 1-2. https://doi.org/10.1109/IRMMW-THz.2017.8066932 
[12] Craft, G., Nussbaum, J., Crane, N., and Harmon, J.P., 2018, "Impact of Extended Sintering Times on Mechanical Properties in PA-12 Parts Produced by Powderbed Fusion Processes," Additive Manufacturing, 22, pp. 800-806. https://doi.org/10.1016/j.addma.2018.06.028

[13] Nussbaum J., and Crane, N., 2018, "Evaluation of Processing Variables in Polymer Projection Sintering," Rapid Prototyping Journal, 24(5), pp. 880-885. https://doi.org /10.1108/RPJ-04-2017-0070

[14] Elvidge, C.D., Keith, D.M., Tuttle, B.T., and Baugh, K.E., 2010, "Spectral Identification of Lighting Type and Character," Sensors, 10(4), pp. 3961-3988. https://doi.org/10.3390 /s100403961

[15] Modest, M., 2013, Radiative Heat Transfer, Academic Press, NY., Chap. 3,9.

[16] "Integrating Sphere Theory and Applications," Labsphere, North Sutton, NH, accessed August 11, 2020, https://www.labsphere.com/site/assets/files/2551/integrating_ sphere_theory_apps_tech_guide.pdf

[17] Wypych, G., 2016, Handbook of Polymers, ChemTec Publishing, Toronto.

[18] Mertens H., and Polman A., 2006, "Depth-Resolved Nanostructure and Refractive Index of Borosilicate Glass Doped with Ag Nanocrystals," Optical Materials, 29(2-3), pp. 326-31. https://doi.org/10.1016/j.optmat.2005.11.002

[19] "Density Determination Kit Instruction Manual," OHAUS Cooperation, Parsippany, NJ, accessed July 28, 2020, https://dmx.ohaus.com/WorkArea/showcontent.aspx?id=25404

[20] "GREEN-Wave Miniature Fiber Optic Spectrometers for VIS-NIR \& OEM," StellarNet Inc, Tampa, FL, accessed July 28, 2020, https://www.stellarnet.us/wpcontent/uploads /StellarNet-GREEN-Wave-SPEC.pdf 


\section{FIGURE CAPTION LIST}

Figure 1 Surface temperature response of an ABS sample irradiated at $660 \mathrm{~nm}$ with $6000 \mathrm{~W} / \mathrm{m}^{2}$ for $0.1 \mathrm{~s}$. The data was retrieved from a $1 \mathrm{D}$ COMSOL simulation modeled with the properties of ABS $\left(\rho=1020 \mathrm{~kg} / \mathrm{m}^{3}, \mathrm{cp}=1386 \mathrm{~J} /(\mathrm{kg} \mathrm{K})\right.$, and $\mathrm{k}=0.2256 \mathrm{~W} /(\mathrm{m} \mathrm{K}))$. The 791,000 element, $8 \mathrm{~mm}$ thick model was thermally insulated on all sides except for the top, which was irradiated and convectively cooled $\left(\mathrm{h}=10 \mathrm{~W} /\left(\mathrm{K} \mathrm{m}^{2}\right)\right)$. Transient surface temperatures are presented when $\mathrm{K}_{\lambda}=0.025 \mu \mathrm{m}^{-1}$ and when $\mathrm{K}_{\lambda} \rightarrow \infty$.

Figure 2 Illustration of the spectral intensity irradiating a black AM polymer fused to a glass slide. The indicated system (dotted rectangle) excludes intensity reflected off interface 1 , and includes intensity reflected off interface 3.

Figure 3 Process for spectral, normal-hemispherical transmissivity measurements using an integrating sphere. A) Radiation enters the sphere unobstructed and current is measured from a photodiode. B) Radiation is obstructed by a sample and current is measured from a photodiode.

Figure 4 Process for spectral, directional-hemispherical reflectivity measurements using an integrating sphere. A) Radiation enters the sphere unobstructed and is partially reflected off a calibration standard, while the resulting diode detector current is measured. B) The calibration standard is replaced with a sample and the process is repeated.

Figure 5 Partially dense ABS (top) and fully dense PLA and Polyamide 12 (bottom) samples

Figure 6 Measured spectrum of the X316 Optoma Projector

Figure 7 Comparing spectral, normal-normal transmissivity measurements obtained using a spectrophotometer and an integrating sphere for a black, fully dense, $109 \mu \mathrm{m}$ thick, PLA sample fused to a glass slide

Figure 8 Transmissivity of black, fully dense PLA (A), ABS (B) and Polyamide 12 (C) samples fused to glass slides, irradiated at $660 \mathrm{~nm}$

Figure 9 Illustration of spectral intensity irradiating a black AM polymer fused to a glass slide mounted to an integrating sphere

Figure 10 Representative spectral absorption coefficient of a polymer fused to a glass slide 


\section{TABLE CAPTION LIST}

Table 1 Comparing spectral, directional-hemispherical reflectivity measurements from an integrating sphere system to spectral, normal-normal reflectivity calculations from Fresnel's equation

Table 2 Absorption coefficient of fully dense AM polymers $\left(\mu \mathrm{m}^{-1}\right)$

Table 3 Absorption coefficient of partially dense AM polymers $\left(\mu \mathrm{m}^{-1}\right)$. The Black $A B S$, PLA, and Polyamide 12 materials were purchased from IC3D, Hatchbox, and EOS respectively. FFF was used to create the ABS and PLA samples, whereas LAPS was used to create the Polyamide 12 samples. 


\section{SUPPLEMENTAL INFORMATION: DERIVATION OF EQUATION 1}

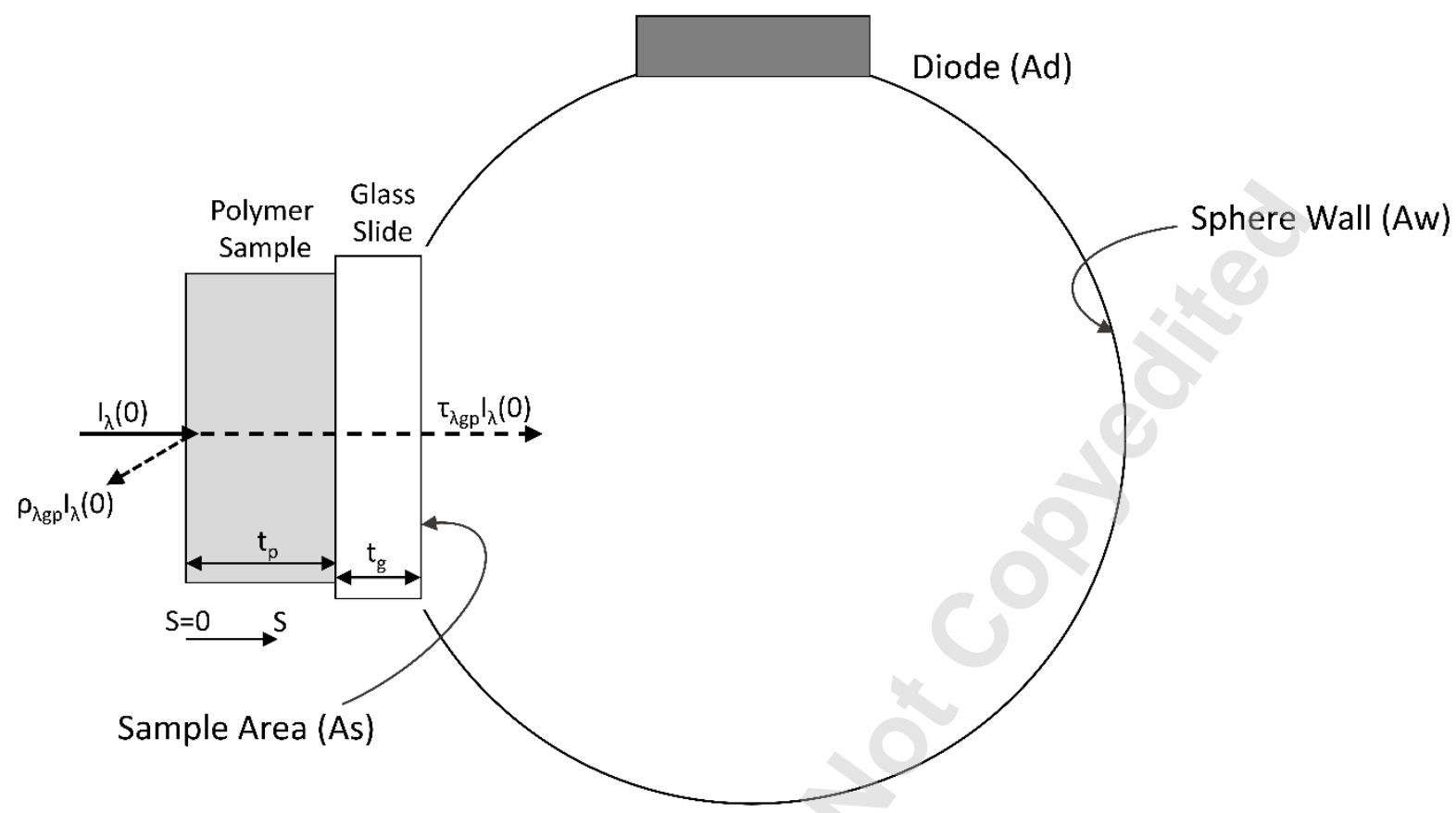

Figure 9: Illustration of spectral intensity irradiating a black AM polymer fused to a glass slide mounted to an integrating sphere

Assume the glass slide and the polymer sample are cold, non-scattering media. The spectral absorption coefficient of the polymer-glass sample can be described with a step function as shown in Figure 10:

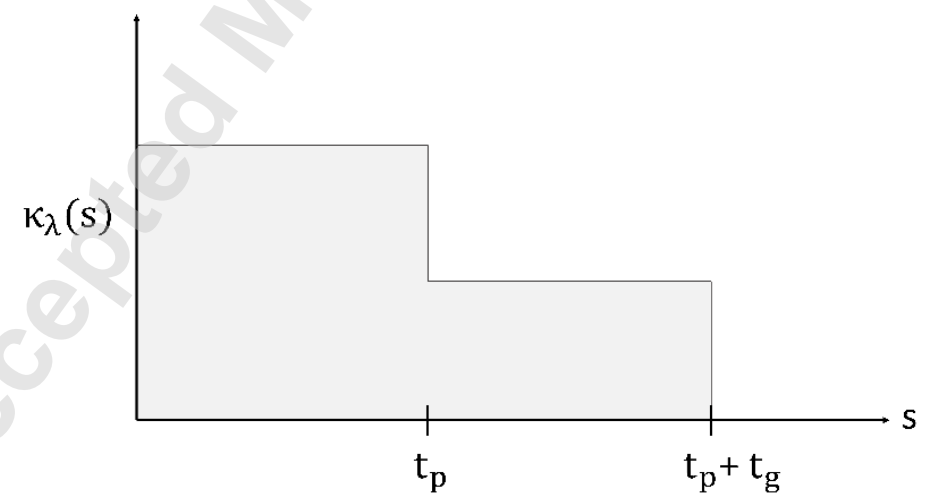

Figure 10: Representative spectral absorption coefficient of a polymer fused to a glass slide

The spectral absorption coefficient is given by Eq. (12) [15]. 


$$
\frac{\mathrm{dI}}{\mathrm{d} s}=-\kappa_{\lambda}(\mathrm{s}) \mathrm{I}_{\lambda}(\mathrm{s})
$$

The boundary condition of this equation on the left surface of the sample $(s=0)$ is:

$$
\mathrm{dI}_{\lambda}(0)=\mathrm{I}_{\lambda_{\mathrm{o}}}\left(1-\rho_{\lambda \mathrm{p}}^{\perp \perp}\right)
$$

Reflections at the polymer sample interface are assumed to be negligible because of the similar indices of refraction. Multiple internal reflections are also assumed to be negligible (see "Justification of Assumptions and Simplifications" in methods section). Separating and integrating Eq. (12) resulted in the following:

$$
\begin{aligned}
& \int_{I_{\lambda_{o}}\left(1-\rho_{\lambda p}^{\perp \perp}\right)}^{I_{\lambda}\left(t_{p}+t_{g}\right)} \frac{d I_{\lambda}}{I_{\lambda}}=-\int_{0}^{t_{p}+t_{g}} \kappa_{\lambda}(s) d s=-\kappa_{\lambda p} \int_{0}^{t_{p}} d s-\kappa_{\lambda, \text { slide }} \int_{t_{p}}^{t_{p+t g}} d s \\
& \ln \left[\frac{I_{\lambda}\left(t_{p}+t_{g}\right)}{I_{\lambda_{o}}\left(1-\rho_{\lambda p}^{\perp \perp}\right)}\right]=-\kappa_{\lambda p} t_{p}-\kappa_{\lambda, \text { slide }} t_{g} \\
& \left.\frac{\mathrm{I}_{\lambda}\left(\mathrm{t}_{\mathrm{p}}+\mathrm{t}_{\mathrm{g}}\right)}{\mathrm{I}_{\lambda_{\mathrm{o}}}\left(1-\rho_{\lambda \mathrm{p}}^{\perp \perp}\right)}=\mathrm{e}^{\left(-\kappa_{\lambda \mathrm{p}} * \mathrm{t}_{\mathrm{p}}\right)} * \mathrm{e}^{\left(-\kappa_{\lambda},\right. \text { slide }} \mathrm{t}_{\mathrm{g}}\right) \\
& \text { Define: } \quad \tau_{\lambda \mathrm{gp}}^{\perp \perp}=\frac{\mathrm{I}_{\lambda}\left(\mathrm{t}_{\mathrm{p}}+\mathrm{t}_{\mathrm{g}}\right)}{\mathrm{I}_{\lambda_{\mathrm{o}}}} \\
& \tau_{\lambda \mathrm{gp}}^{\perp \perp}=\frac{\mathrm{I}_{\lambda}\left(\mathrm{t}_{\mathrm{p}}+\mathrm{t}_{\mathrm{g}}\right)}{\mathrm{I}_{\lambda_{\mathrm{o}}}}=\mathrm{e}^{\left(-\kappa_{\lambda \mathrm{p}} * \mathrm{t}_{\mathrm{p}}\right)} * \mathrm{e}^{\left(-\kappa_{\lambda},\right. \text { slide }}{ }^{\left.* \mathrm{t}_{\mathrm{g}}\right)} *\left(1-\rho_{\lambda \mathrm{p}}^{\perp \perp}\right)
\end{aligned}
$$

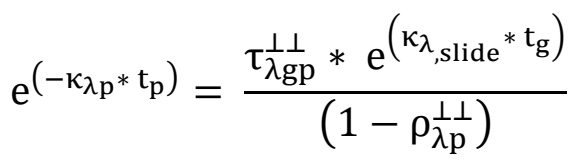

$$
\begin{aligned}
& \kappa_{\lambda p}=-\frac{1}{t_{p}} \ln \left[\frac{\tau_{\lambda \mathrm{gp}}^{\perp \perp} * \mathrm{e}^{\left(\kappa_{\lambda}, \text { slide }^{* \mathrm{t}_{\mathrm{g}}}\right)}}{\left(1-\rho_{\lambda \mathrm{p}}^{\perp \perp}\right)}\right] \\
& \text { Define: } \quad \tau_{\lambda \mathrm{g}}^{\perp \perp}=\mathrm{e}^{\left(-\kappa_{\lambda}, \text { slide }{ }^{*} \mathrm{tg}\right)}
\end{aligned}
$$




$$
\kappa_{\lambda p}=\frac{\ln \left(\frac{\left(1-\rho_{\lambda p}^{\perp \perp}\right) \tau_{\lambda g}^{\perp \perp}}{\tau_{\lambda g p}^{\perp \perp}}\right)}{t_{p}}
$$

